\title{
Using Dance \& Movement to Enhance Spatial Awareness Learning
}

\author{
By Barbara Ann Temple ${ }^{*}$ Kathryn Bentley ${ }^{\dagger}$, David K. Pugale ${ }_{*}^{*}$, \\ Natalie Blundell ${ }^{\S}$ \& Carlos Miranda Pereyra
}

\begin{abstract}
By accessing creative portions of the brain through dance, Pre-K students can more easily learn math concepts like spatial awareness and critical math knowledge prior to formal assessment in elementary school. This early foundational learning creates educational equity by resulting in a month of additional math learning before ever stepping into an elementary classroom. At a very fundamental level, when students have access to math learning in Pre-K through the performing arts, they are more than a month ahead of their non-PreK peers when they enter a Kindergarten classroom, (Ludwig, Marklein, \& Song, 2016). Arts-integrated math learning engages both hemispheres of the brain and all types of students, especially English Language Learners (ELL) and those from lower socioeconomic status, benefit academically from such experiences. Math and movement residencies bring equity and access to the classroom by preparing students with critical foundational knowledge in math prior to encountering formal math concepts in Kindergarten.
\end{abstract}

Keywords: dance \& movement, geometry, kinesthetic learning, social constructivism, spatial awareness.

\section{Introduction and Aims of Research}

Experiential learning in and through the arts benefits young students in Pre-K classrooms by engaging both creative right-brain activity with the more rational functions of the left brain. The average traditional classroom teacher (CT) does not possess the knowledge or skills to engage the brain holistically and simultaneously in this way. These strategies are not traditionally taught in public school teacher training, thereby creating disparities in equity and access for students. Mayer (2017) posits that the application of psychology to education has been ineffective primarily because it has been operating as a one-way street where educators have attempted to apply principles from psychology and neuroscience.

This inequity can be mitigated through arts-infused learning. Wolf Trap (WT) Institute for Early Learning Through the Arts administers seven-week artsintegrated residencies that provide Pre-K teachers with skills that work to engage

\footnotetext{
*Vice President, Education Arts \& Science Council (ASC), USA.

${ }^{\dagger}$ Affiliate Director, North Carolina Wolf Trap Arts \& Science Council (ASC), USA.

*UNC Charlotte Center for Science, Technology, Engineering, and Mathematics (STEM) Education, USA.

${ }^{\S}$ Artistic and Executive Assistant, National Orchestra at the John F. Kennedy Center for Performing Arts, USA.

*** Davidson College Impact Fellow Arts \& Science Council (ASC), USA.
} 
students holistically. Professional Teaching Artists (TA) work with CTs to acquire arts strategies to be used throughout their careers.

\section{The Aim of the Research is to Answer these Questions}

- What happens to Pre-K students' acquisition of spatial awareness skills when they experience math literacy through dance and movement?

- How does learning improve when the performing arts are used to teach math?

\section{Literature Review}

Theorists and early education scholars advocated for interdisciplinary learning in the traditional classroom. John Dewey, an early twentieth century education reformer, argued for the importance of active learning and of drawing on personal experience when in the classroom (Dewey, 1902). Similarly, developmental psychologist Howard Gardner (1999) argued for the existence of multiple, categorical, intelligences within the singular human intellect. These two assertions combine to create a compelling argument for breaking away from traditional rote learning experiences and turning toward more real-world, creative, interdisciplinary experiences that create educational equity for students with diverse learning abilities and backgrounds.

Research reveals that children from a lower socioeconomic status often start Kindergarten significantly behind their peers (O’Brien \& Dervarics, 2007). This opportunity gap between students of poverty and students of medium or high socioeconomic status is narrowed through Pre-K programs in public schools that allow more students to perform at grade level when entering Elementary School. Additionally, there is some evidence that this gap would widen without schooling and that students from lower socio-economic groups experience a 'summer learning loss' at a higher rate than peers (Bradbury, Corak, Waldfogel, \& Washbrook, 2017). The social constructivist approach to Wolf Trap learning, exercised by both teachers and students, establishes a foundation for continued success in math learning. As students engage in the social activity of dance during math lessons, they learn more from engaging with each other and with the teacher than when learning independently. This situated cognition of learning spatial geometry through participating in dance is strengthened by students' social interactions with their peers (Vygotsky, 1978). As Pre-K students first learn about the notion of space and how they exist within the space around them, they begin learning spatial geometry. When young children discover new pathways in space that represent early spatial geometry, they gain self-confidence because the arts empower them to be actively engaged in their own learning (Pugalee, Harbaugh, \& Quach, 2009; Temple, 2007; Holloway, 2001; Burton, Horowitz, \& Abeles, 1999; Catterall, Chapleau, \& Iwanaga, 1999; Eisner, 1998).

Success in STEAM disciplines (Science, Technology, Engineering, Arts and Mathematics) is closely linked to spatial abilities. A study at the University of 
Chicago found that "Improving children's spatial skills may have positive impacts on their future success in [STEM]...by enhancing numerical skills that are critical for achievement in all STEM fields," (Gunderson, Ramirez, Beilock, \& Levine, 2012). Specifically, acquiring spatial awareness will help students "mentally manipulate objects" which will serve them in the future when reading graphs and understanding diagrams (Gunderson et al., 2012). These studies indicate that these skills, required of any engineer or scientist, must be taught as early as possible. Wolf Trap math residencies translate to higher scores in math assessment. Through a grant from the U.S. Department of Education, the study on improved math performance in Wolf Trap residencies revealed students acquired an additional 26 days of math learning (Ludwig et al., 2016). In a similar study, the mean gain score for residency classrooms in mathematics was two times higher than non-residency classrooms (Klayman, 2004).

Figure 1. Using Scarves \& Body Movement to Show an Understanding of Position Words (i.e., under)

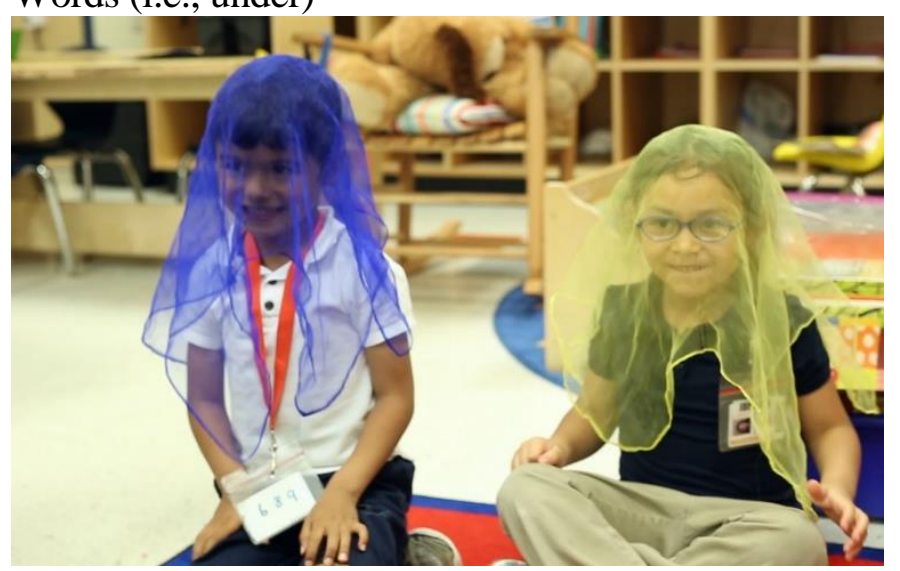

Source: Driscoll, 2017.

What does it mean to be spatially aware? Spatial awareness can be defined as "an awareness of the body in space, and the child's relationship to the objects in the space," (Hohmann, Weikart, \& Epstein, 2008). As children's brains develop, so too does their understanding of their body's relation to the world around them. At first it is difficult for young children to understand early spatial concepts such as "on," "under," "over," and "behind." Children develop spatial awareness through whole-body activities (see Figure 1). Once children understand early spatial concepts, they can then advance to more challenging math concepts in the future. For many preschool children, an understanding of spatial concepts predicts later success in math, reading, and following directions.

Why is spatial awareness important to math development? Spatial awareness is an important aspect of early childhood development. In many classrooms across the country, teachers are not stressing the concepts of geometry and spatial awareness. This is a disservice to children as they begin their school career. The extent of geometry instruction for many children is the act of sorting shapes made from cut outs and identifying the basic shapes (i.e., circle, square, triangle). Mathematical competency for children relates to their spatial awareness, which 
includes a recognition of shapes in their surrounding environment and involves counting objects in their surroundings. On a neuropsychological level, similar parts of the brain are used when performing spatial tasks as when performing number tasks. This spatio-numerical link is a foundation of an imperative for teachers: an intentional focus on spatial reasoning and geometry at an early age better prepares students for mathematics throughout their educational careers. Unfortunately, children who are less capable of reading lines and simple objects around them will more than likely also be unable to recognize forms and geometric plans. Children are capable of diving deeper into these concepts that they are given credit for. This early instruction will influence their learning in other areas of the school curriculum. So connected are spatial reasoning and mathematics that the spatial thinking skills of children can be used to predict math competency for adults (Yarmohammadian, 2014; Cheng \& Mix, 2013; Hubbard, Piazza, Pinel, \& Dehaene, 2005; Walsh, 2003; Dehaene, Bossini, \& Giraux, 1993).

While there may be a clear connection between mathematics and spatial thinking, its significance is integral to other areas of development, from physical education to art and language. Despite its prominence of spatial reasoning in various subjects, especially math, and recommendations by the NCTM that at least $50 \%$ of mathematic instruction be focused on spatial thinking, geometry and spatial reasoning continue to remain undervalued and under-taught (Moss, Bruce, Caswell, Flynn, \& Hawes, 2016; Bruce, Flynn, \& Moss, 2012; Sarama \& Clements, 2009; National Council of Teachers of Mathematics [NCTM], 2006).

Figure 2. Building Spatial Awareness by Forming Shapes with Their Bodies
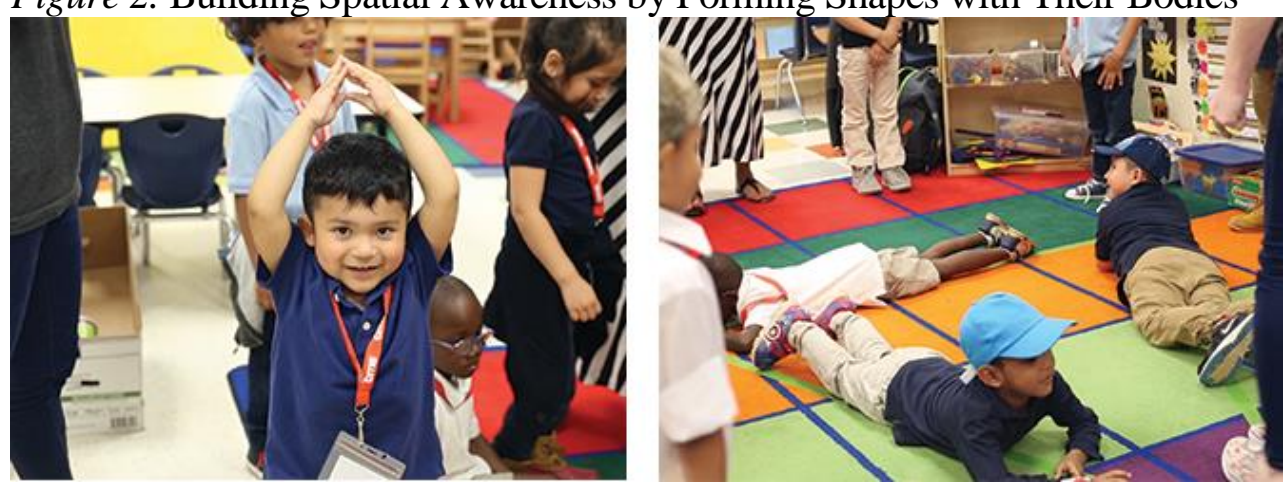

Source: Driscoll, 2017.

How does engaging in dance \& movement promote increased spatial awareness? Dance and movement are key to the development of spatial abilities in children. Physical movement is a child's natural first approach to learning. Dance elements such as body awareness, pathways, and creating shapes with the body all build spatial awareness in young children (see Figure 2). Integrating these dance elements into daily math lessons allows possibilities for exploring locomotor and non-locomotor movements. During dance or movement exercises, a child's understanding of spatial language enables him/her to move one's body through space.

\section{Background and Ideology of Wolf Trap Residencies}


Wolf Trap residencies are a partnership between a Teaching Artist and an early childhood educator. The partnership provides professional development for early childhood educators while helping children learn through active participation. To qualify as a Wolf Trap Teaching Artist, individuals are required to have at least three years of experience working professionally in their artistic field. The artists become certified Wolf Trap professionals through intensive training by master Teaching Artists from the Wolf Trap Institute for Early Learning through the Arts headquarters. During the training, the Teaching Artists are instructed in early childhood developmental domains, developmentally appropriate practice, twenty-first century skills, intentional teaching, lesson design and coaching. They observe the skills and strategies of master Teaching Artists while designing their own arts-infused lessons.

The goal of the Wolf Trap Institute for Early Learning through the Arts is to provide professional development for each Pre-K and Kindergarten Classroom teacher for a period of three years (see Figure 3). In doing so, the classroom teacher has the opportunity to receive professional development training in all three of the performing arts: dance and movement, music, and drama. After three years of Wolf Trap residencies, a classroom teacher develops a good understanding of arts integration. Between residencies classroom teachers are able to have time to implement and practice the strategies presented during a residency. Wolf Trap has an exponential positive effect on students: Teachers are not only benefitting the three classrooms in which the residencies are administered, they continue to benefit every classroom they teach for the rest of their teaching career as well as in classrooms where they have shared with their colleagues how to use the performing arts to teach math concepts.

Figure 3. Engaging a Teacher \& Student in Movement Activity

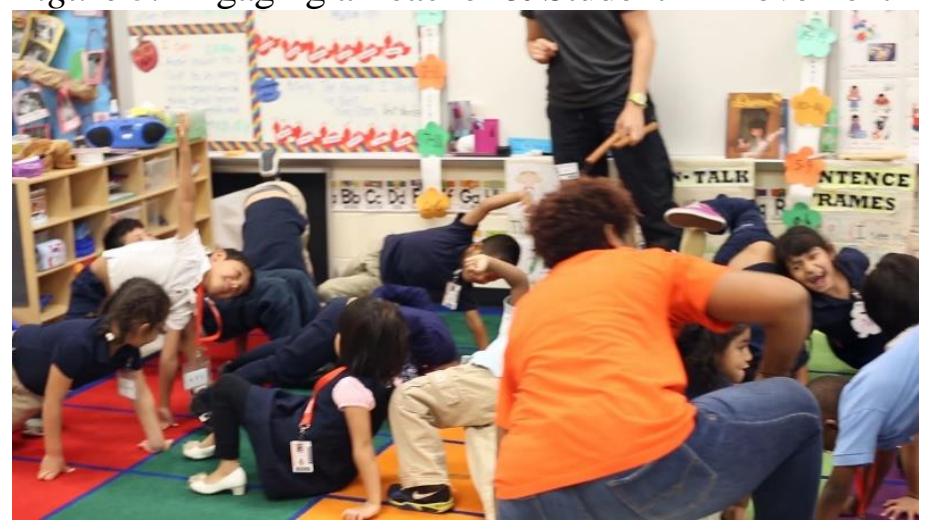

Source: Driscoll, 2017.

\section{Case Study Methodology}

The authors used ethnographic techniques of interview and observation to collect teacher narratives on student math learning in a high poverty school. The authors used these techniques to understand how the arts specifically created equity within Pre-K classrooms. 


\section{Case Study Setting}

Mecklenburg County, North Carolina has a population just over 1 million and demographic data reports that just under half the county's population is a nonWhite minority (United States Census Bureau, 2015). In the local CharlotteMecklenburg School system (CMS), 77 of the total 170 public schools are categorized as Title I (high poverty)(Charlotte-Mecklenburg Schools, 2016). Creekside Elementary School houses 39 Kindergarten through 5th grade classrooms, and 16 Pre-K classrooms. Socioeconomic data revealed 98.89 percent of four-person families whose children attend Creekside earn an annual income of $\$ 24,600$ or less (Department of Health and Human Services, 2017).

\section{Data Collection}

The authors interviewed two Pre-K teachers directly involved in a math-based WT Residency in Dance and their two corresponding TAs for a 7-week residency in their respective classrooms. For the purpose of this particular case, we focused on the concept of spatial awareness in Geometry lessons. Both Pre-K teachers were asked the same questions: What specific spatial awareness words, positions, and exercises did your students learn through dance/ movement and why were they important? What were the specific components of dance/movement that helped your students increase their spatial awareness? We conducted the interviews at the conclusion of the 7-week residency and both teachers were present during the interview period.

Participants. The WT STEM (Math) residencies in dance and movement were conducted in two Pre-K classrooms of 18 students each. Ms. Jones' class consisted of four native English speakers and 14 non-English speakers. Elizabeth, a Wolf Trap Teaching Artist in dance \& movement, worked with Ms. Jones' classroom for the math residency in this case. Together, Elizabeth and Ms. Jones identified specific math learning goals and arts strategies for the residency. First, students would understand and describe spatial relationships and shapes through body strength, balance, flexibility and stamina. Second, students would increase their ability to move their bodies in space (running, jumping, and skipping).

Ms. Graham taught the second Pre-K classroom consisting of three native English speakers and 15 non-English speakers. Stacy, a Wolf Trap Teaching Artist in dance \& movement, worked with Ms. Graham's Pre-K students. Based on the specific needs of her students, Ms. Graham worked with Stacy to identify specific math learning goals and arts strategies for the residency. First, students should be able to understand and describe spatial relationships, shapes, and patterns through axial, locomotor, non-locomotor, and body shapes. Second, students should be able to understand and describe spatial relationships, shapes, and patterns by moving in time to different patterns of beat, rhythm, and music. 


\section{Data Analysis}

Through qualitative data, the authors uncovered fascinating findings that ultimately helped answer the two main research questions. Below, the interview responses from classroom teachers and Teaching Artists are categorized to answer these two research questions. One question focused on the specific acquisition of new math knowledge through dance and movement. The second question focused specifically on how learning improved through the performing arts.

\section{What Happened to Pre-K Students' Acquisition of Spatial Awareness when Math Lessons were Integrated with Dance and Movement?}

The kinesthetic act of movement through dance created access for Pre-K students to acquire spatial awareness. Dance and movement were key to the development of spatial abilities in the children and resulted in active engagement, attention to focus, and increased self-confidence (see Figure 4). Integrating dance into daily curriculum supported acquisition of spatial understanding and increased self-awareness.

Figure 4. Developing Self-Confidence While Taking Risks in Front of Peers

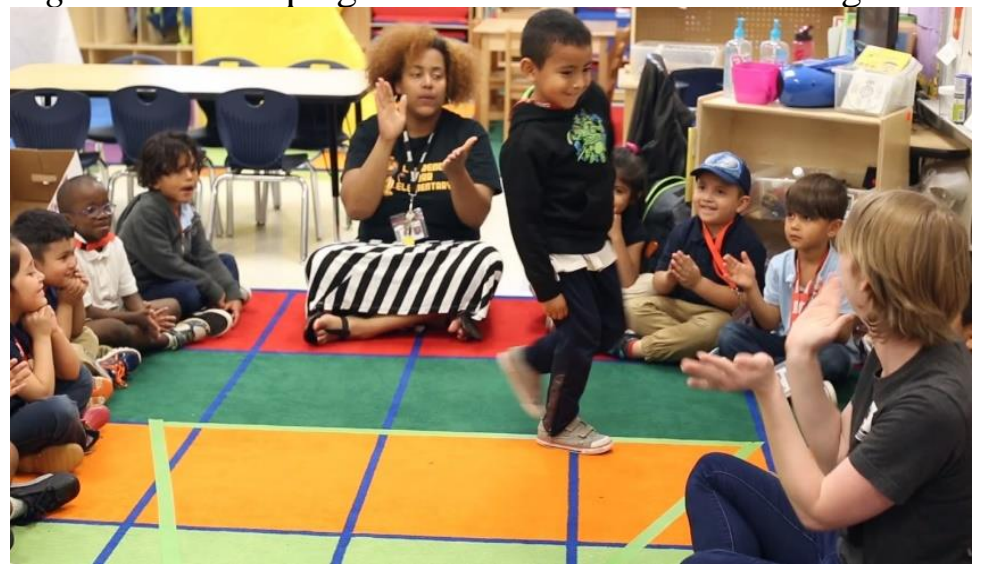

Source: Driscoll, 2017.

Elizabeth: Being spatially aware allows the children to move in a group setting with other bodies without safety issues...They learned how to control their bodies.

When math and dance were combined to teach students about spatial awareness, the classroom became safer, focused, and accident-free. Fewer physical accidents in the classroom created a healthier learning environment where students were more capable of sustained learning for long periods of time.

Stacy: Dance inherently requires and develops constant spatial awareness. Dancing in groups allows children to gain a general understanding of how much space their body takes up and how to move safely next to their friends and objects in the room. 
This newly acquired sense of personal space transferred to tasks that students completed as a group. The improvement of spatial awareness through math and dance allowed entire classrooms to complete simple daily tasks more efficiently.

Ms. Jones: The exercises [where students] walk on different shapes and lines taped to the floor helped them walk in a straight line [as a group] in the hallway, for example.

These seemingly simple tasks of walking in a straight line as a classroom to the cafeteria are profoundly difficult for a Pre-K child with little to no spatial awareness. However, when the children in this case learned these skills, teachers saw major improvements in the efficiency of moving Pre-K students from point A to point $\mathrm{B}$.

Additionally, crossing the midline of the body helps build pathways in the brain and is an important skill required for the appropriate development of motor and cognitive skills. Many Pre-K activities require a child's ability to cross the midline of the body. By crossing a hand, arm, foot, or leg to the opposite side of the body, children build increased brain functions to perform more advanced tasks. When you move your arms or legs across to the other side of the body, both sides of the brain are activated making reading, comprehension, writing, and math easier to take place (see Figure 5). Children will also have trouble with self-care skills, sports and physical activities when they have not developed the ability to cross the midline. Such activities, through dynamic development of imagery, show how the use of body movements and other motor components connect visualization and movement in supporting learning (Presmeg, 2006; 1991).

Figure 5. Crossing the Midline while Building Pathways in the Brain

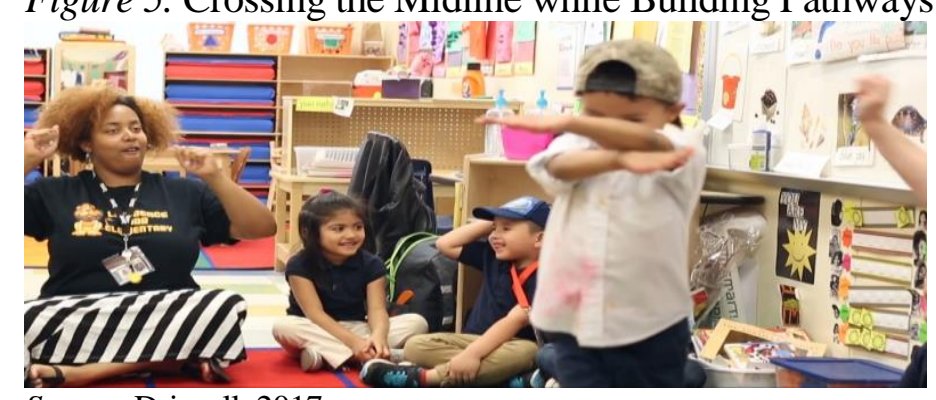

Source: Driscoll, 2017.

The crossing from one side of the body to the other side is a type of bilateral movement. Children who are unable to develop this bilateral skill often have difficulty learning to read. Similar to bilateral body movements, reading requires the eyes to move from left to right across the page and across the midline of the brain. When young children lack practice in bilateral movements, the task of moving eyes from left to right across a page can be taxing for the eyes, resulting in the inability to understand the meaning of the text. Furthermore, bilateral skills also assist in the development of handwriting skills. Greenes, Ginsburg, and Balfanz (2004) report that body movements and the related sounds are effective in supporting young children's understanding of mathematics concepts. Other researchers have shown that body movements have a positive impact on young 
students' cognition learning and academic achievement (Chandler \& Tricot, 2015; Erikson, Hillman, \& Kramer, 2015; Bartholomew \& Jowers, 2011; Tomporowski, Davis, Miller, \& Naglieri, 2008).

In this particular case, there were many dance and movement activities that developed cross-lateral motions. As children moved along different pathways, repeated dance patterns, or created body shapes, they connected these movements with a growing understanding of geometric concepts. At the Pre-K level, some children are only familiar with the basic shapes, (i.e., circle, square, and triangle). They may know the name of the shape but are unable to describe the shape attributes. During the dance activities, students were given the opportunity to learn the vocabulary needed to describe different geometric shapes. They learned how to sort shapes and how to use attributes to describe why a figure does or does not belong to a shape category.

\section{How Did Learning Improve when the Performing Arts Were Used to Teach Math?}

The performing art of dance - when used in math lessons - helped students feel more comfortable breaking from more traditional learning, thereby they gained comfort in risk and newness.

Stacy: As students' spatial awareness develops, they are able to make more exciting choices and begin to take risks and problem solve. The benefits of practicing and developing these skills in movement experiences positively affect the ways in which children interact with space in the classroom and at home (ex: following directions, fine and gross motor skills, playing safely with others)

Ms. Graham: I enjoy seeing my students make connections between the Wolf Trap residency and their real life. We use position words when we're out on the playground. I try to extend the lessons and draw these connections by saying "you're going down the slide" or "you're under the slide." They really use these words now.

By increasing children's spatial awareness through dance and math in the classroom, the teachers also increased students' opportunities to expand their learning beyond the walls of the classroom. As students increased their spatial awareness, they also increased their vocabulary. This was evident as students were better able to recognize and describe shapes they noticed in the environment They were able to use what they learned to talk about situations and experiences in the classroom, cafeteria, playground and in conversation about things that happened in their daily lives. They recognized shapes in books they were reading and on the walls around the school. Their school hallways were designed with geometric shapes and the children became proficient at naming shapes as they stepped on them. 
Learning the concept of spatial awareness through dance and repetition contributed to the development of self-efficacy in the Pre-K students.

Ms. Jones: I saw their confidence grow with identifying and describing shapes. Toward the beginning the students went directly to the station with the shape they knew best and felt most comfortable describing. But toward the end, I saw them feel more comfortable going to a shape that was newer to them.

Ms. Jones' observations of her students' increased self-confidence in experiencing shapes through movement is important for understanding math learning. Something equally as important took place within the students: they took risks and developed self-efficacy as they believed they could attempt to describe a shape unfamiliar to them. Their active participation in learning the concept of shapes through dance and movement enabled them to experiment with new learning in a safe environment.

Ms. Graham: I saw a confidence boost when we were learning shapes. Toward the beginning, I saw the students copying each other when they were asked to make shapes with their bodies. But toward the end, it was amazing to see the variety of shapes. They were being creative. Everybody finally felt comfortable to make their own shape.

The student-centered approach to math literacy learning through the arts fostered a socially-constructed new knowledge and understanding of spatial awareness. Notice that as the students' self-confidence grew, their creativity also increased throughout the residency. Within this participatory classroom, students not only learned new shapes through teacher instruction but also learned new shapes from one another (Vygotsky, 1978). This social constructivist approach to math literacy learning through the arts empowered students to become leaders within the collaborative classroom. In that leadership role, students became active participants in their own learning (see Figure 6).

Figure 6. Learning New Concepts through Social Interaction

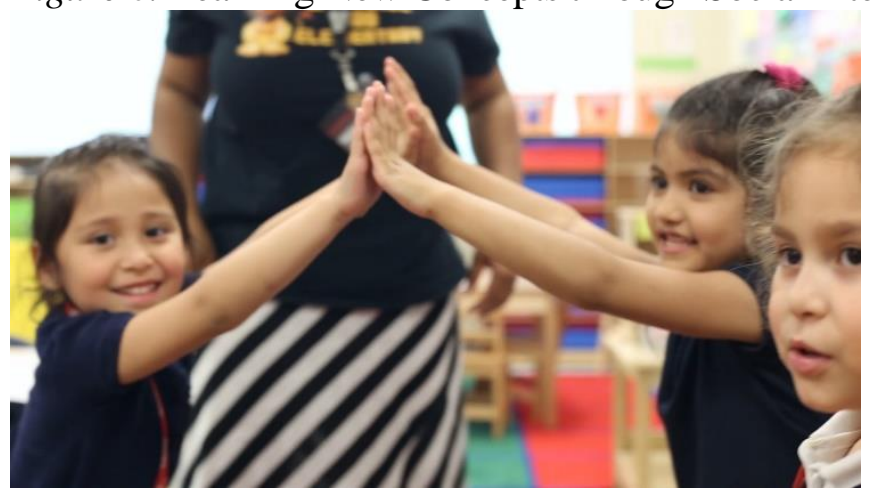

Source: Driscoll, 2017.

Ms. Jones: I see a big difference in participation [now that the residency is complete]. They weren't so sure and didn't want to join in during the first few 
sessions. But toward the end, they have to lead the song, and you can see that they get it, you can see they gained confidence.

In this case study, the arts cultivated access to a new language of math. Regardless of the linguistic capital each student brought to the classroom at the beginning of the residency, the arts removed barriers in learning new math concepts. By creating a safe space and "moments of inclusion," new math skills were developed through social interaction more easily (Temple, 2007; Holloway, 2001; Bourdieu \& Passeron, 1977) (see Figure 7).

Figure 7. Empowered as active participants in their own learning

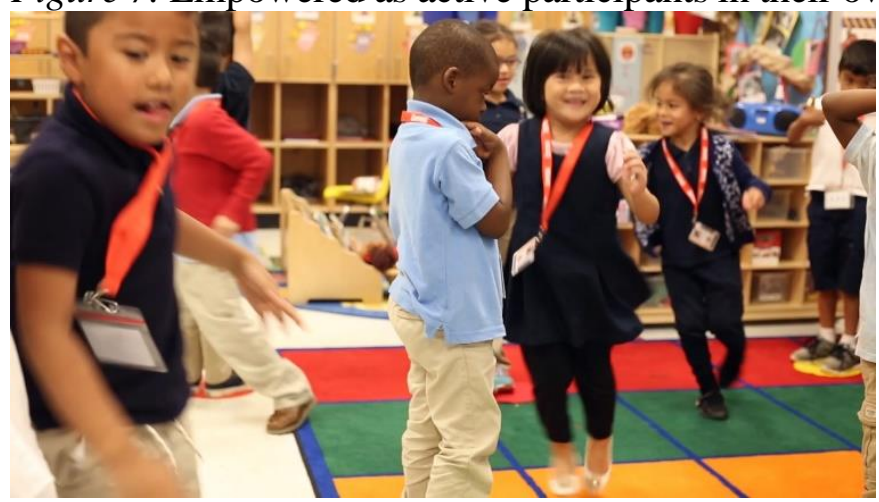

Source: Driscoll, 2017.

Ms. Graham: The residencies help reinforce [position] words that normally pose a challenge like "behind," "over," "under." We used the snowman from the story, so they got in front of the snowman, behind the snowman. At the end of the residency... they were finally getting the hang of it.

Together, the Pre-K students developed a common language centered on spatial awareness using position words within their math lesson. Students finally understood their own body's relation to space and objects in space (see Figure 8).

Figure 8. Listening \& Following Directions as the Teaching Artist Demonstrates Position Words with Scarves

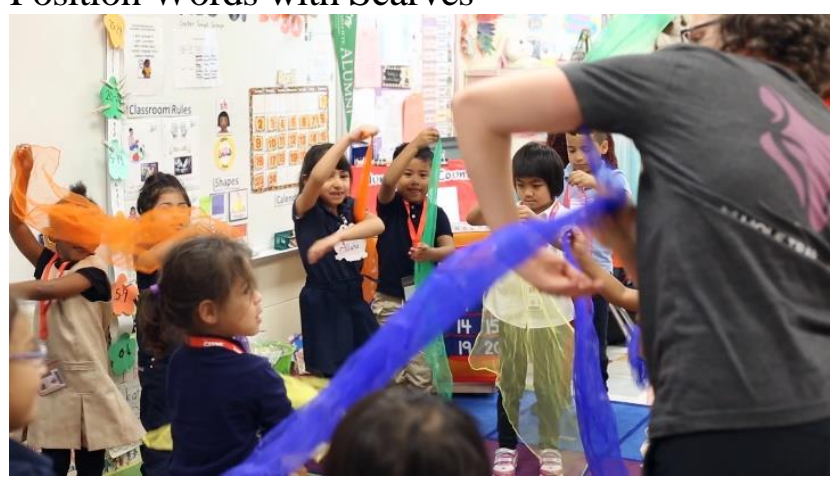

Source: Driscoll, 2017. 


\section{Implications}

Pre-K learning prepares students for learning in Elementary Education, contributing to their readiness for future learning and success later in life. Formal assessments which identify students for accelerated learning programs identify "spatial intelligence" as one of four identified areas (West Windsor-Plainsboro, 2015). By demonstrating a strong spatial intelligence, paired with talents in other academic arenas, students have an increased chance of being chosen for an accelerated academic program. Students who are exposed to and gain spatial awareness skills as early as Pre-K have more experience with these processes and are therefore more likely to meet, if not exceed, math learning standards for their age.

The Partnership for $21^{\text {st }}$ Century Learning (2016) research coalition created a framework which identifies skills that will prepare this next generation of students for future complex work environments: creativity, critical thinking, communication, and collaboration. This framework responds to the Mayer (2017) recommendations for using psychology and science to make unique contributions: a focus on subject area learning, use of authentic learning tasks, a focus on cognitive processes while learning and learning outcomes, and attention to instructional techniques that guide cognitive processing.

The Wolf Trap residencies outlined in this case provided the perfect foundational learning environment for Pre-K students to begin an educational journey directly aligned with our nation's goals in mind. The knowledge of spatial sense acquired through dance and movement during math lessons created opportunities for continued learning and reinforcement in other instructional arenas during the school day. Additionally, spatial thinking and geometry learning at the Pre-K level "reduces differences related to gender and socioeconomic status that may impede full participation in a technological society," (Get Set for School, 2011). The student acquisition of spatial awareness through dance created an equitable opportunity for Pre-K students to be better prepared for Kindergarten and for a successful life in a complexifying society.

\section{Conclusions}

This qualitative case study supports the existing, related research. The case study revealed that as a result of Wolf Trap dance residencies in math lessons, Pre-K students acquired strong foundational geometry skills, resulting in increased confidence, participation, and formation of real-life math connections outside the classroom. The following were the results of the qualitative case study centered on Pre-K students who experienced movement residencies in math experiences at Creekside Elementary School:

- Increased knowledge in spatial awareness and early geometry concepts including: Recognized and described the attributes of common shapes; Understood spatial relationships; Used position words that identified 
different positions in space; Understood positional words in order to follow specific directions during transitions; Used the body to make physical representations of the four common shapes; Applied movement activities to reinforce concepts of shapes

- Increased confidence when speaking in front of peers

- Increased willingness to participate

- Increased connections to math concepts outside classroom

From these results, the researchers concluded that Wolf Trap residencies met and actually exceeded local and national classroom standards. The teachers' new creative abilities acquired from the residency allowed them to engage all students in math lessons, regardless of language limitations, not only within the classroom but also outside the walls of the classroom. The students' increased confidence and willingness to participate in math-focused movement residencies displayed a positive relationship to math learning, suggesting that these students will likely approach Kindergarten math lessons with willingness, excitement, and a solid foundation in math learning.

\section{Acknowledgements}

Our thanks to the wonderful classroom teachers and Wolf Trap Teaching Artists without whom our work would not have been possible. We would also like to thank ASC Studio 345 Teaching Artist Nicole Driscoll for her wonderful photo contributions.

\section{References}

Bartholomew, J.B., \& Jowers, E.M. (2011). Physically active academic lessons in elementary children. Preventive Medicine, 52(Suppl), S51-S54.

Bourdieu, P., \& Passeron, J.C. (1977). Reproduction: In education, society, and culture. London: SAGE Publications.

Bradbury, B., Corak, M., Waldfogel, J., \& Washbrook, E. (2017). Too many children left behind. Schools and Society: A Sociological Approach to Education.New York: Russell Sage Found.

Bruce, C., Flynn, T., \& Moss, J. (2012). Early mathematics: Challenges, possibilities and new directions in the research (Mathematics for Young Children: Literature Review). Comprehensive literature review submitted to the Literacy and Numeracy Secretariat, Ontario Ministry of Education. Toronto, Ontario, Canada.

Burton, J., Horowitz, R., \& Abeles, H. (1999). Learning in and through the arts: Curriculum Implications. In Edmund B. Fiske, (Ed.), Champions of Change: The Impact of the Arts on Learning (pp.36-46). Washington, DC: President's Committee on the Arts and Humanities.

Catterall, J.S., Chapleau, R., \& Iwanaga, J. (1999). Involvement in the arts and human development: Extending an analysis of general associations and introducing the special cases of intensive involvement in music and theatre arts. (Americans for the 
Arts Monograph No. 11). Los Angeles, CA: University of California at Los Angeles, Graduate School of Education and Information Studies.

Chandler, P., \& Tricot, A. (2015). Mind your body: The essential role of body movements in children's learning. Educational Psychology Review, 27(3), 365-370.

Charlotte-Mecklenburg Schools. (2016). All school SES level 2016. Charlotte, NC.

Cheng, Yi-Ling, \& Mix, Kelly S. (2013). Spatial training improves children's mathematics ability. Journal of Cognition and Development, 15(1), 2-11.

Dehaene, S., Bossini, S., \& Giraux, P. (1993). The mental representation of parity and number magnitude. Journal of Experimental Psychology: General, 122(3), 371-396.

Dewey, J. (1902). The Child and the Curriculum. Chicago, Illinois: The University of Chicago Press.

Department of Health and Human Services. [DHHS] (2017). Annual Update of the HHS Poverty Guidelines. (FR Doc. 2017-02076).

Eisner, E.W. (1998). The kind of schools we need: Personal essays. Portsmouth, NH: Heinemann.

Erickson, K.I., Hillman, C.H., \& Kramer, A.F. (2015). Physical activity, brain, and cognition. Current Opinion in Behavioral Sciences, 4, 27-32.000

Gardner, H. (1999). Intelligence Reframed: Multiple Intelligences for the $21^{\text {st }}$ Century (32). New York, NY: Basic Books.

Get Set for School. (2011). Get Set for Readiness, Writing, Language, and Math: A Pre-K Roadmap for School Success. Gaithersburg, MD.

Greenes, C., Ginsburg, H. P., \& Balfanz, R. (2004). Big math for little kids. Early Childhood Research Quarterly, 19(1), 159-166.

Gunderson, E., Ramirez, G., Beilock, S., \& Levine, S. (2012). The relation between spatial skill and early number knowledge: The role of the linear number line. Developmental Psychology, 48(5), 1229-41. The University of Chicago: Department of Psychology and Committee on Education.

Hohmann, M., Weikart, D., \& Epstein, A. (2008). Educating Young Children: Active Learning Practices for Preschool and Child Care Programs (428). Ypsilanti, MI: High Scope Press.

Holloway, D.L. (2001). Authoring identity and agency in the arts. Dissertation Abstracts International, 62(02), 426.

Hubbard, E.M., Piazza, M., Pinel, P., \& Dehaene, S. (2005). Interactions between number and space in parietal cortex. Nature Reviews Neuroscience, 6(6), 435-448.

Klayman, D. (2004). Executive summary of the final evaluation report of fairfax pages professional development project: An effective strategy for improving school readiness. Potomac, MD: Social Dynamics LLC.

Ludwig, M.J., Marklein, M.B., \& Song, M. (2016). Arts Integration: A Promising Approach to Improving Early Learning. Washington, DC: American Institutes for Research.

Mayer, R.E. (2017). How can brain research inform academic learning and instruction? Educational Psychology Review, 29(4), 835-846.

Moss, J., Bruce, C.D., Caswell, B., Flynn, T., \& Hawes, Z. (2016). Taking Shape: Activities to Develop Geometric and Spatial Thinking. Toronto, CA: Pearson Canada, Inc.

National Council of Teachers of Mathematics, Inc. [NCTM] (2006). Curriculum Focal Points. Reston, VA: Reys, B.

O'Brien, E. M., \& Dervarics, C. (2007). Pre-Kindergarten: What the research shows. Alexandria, VA: Center for Public Education.

Pugalee, D.K., Harbaugh, A., \& Quach, L.H. (2009). The human graph project: Giving students Mathematical power through differentiated instruction. In M.W. Ellis (Ed.), 
Mathematics for Every Student: Responding to Diversity, Grades 6-8. National Council of Teachers of Mathematics.

Partnership for 21st Century Learning [P21]. (2016). Framework for 21st Century Learning. Washington, DC: P21.

Presmeg, N.C. (2006). Research on visualization in learning and teaching mathematics. Handbook on the Psychology of Mathematics Education, 205-235.

Presmeg, N. C. (1991). Classroom aspects which influence use of visual imagery in high school mathematics. In F. Furinghetti (Ed.), Proceedings of the $15^{\text {th }} P M E$ International Conference, 3, 191- 198.

Sarama, J., \& Clements, D. (2009). Building Blocks and Cognitive Building Blocks: Playing to know the world mathematically. American Journal of Play, 1, 313-337.

Temple, B.A. (2007). Creating studios of literacy learning through the arts: A narrative case study in arts integration for urban high school education. Charlotte, NC.: The University of North Carolina at Charlotte.

Tomporowski, P. D., Davis, C. L., Miller, P. H., \& Naglieri, J. A. (2008). Exercise and children's intelligence, cognition, and academic achievement. Educational Psychology Review, 20, 111-131.

United States Census Bureau. (2015). QuickFacts: Mecklenburg County, North Carolina. Retrieved from www.census.gov.

Vygotsky, L.S. (1978). Mind in society: The development of higher psychological processes. Cambridge: Harvard University Press.

Walsh, V. (2003). A theory of magnitude: common cortical metrics of time, space and quantity. Trends in Cognitive Sciences, 7(11), 483-488.

West Windsor-Plainsboro Regional School District. (2015). Gifted and Talented Program Review Internal Report. Plainsboro, NJ.

Yarmohammadian, A. (2014). The Relationship between Spatial Awareness and Mathematic Disorders in Elementary School Students with Learning Mathematic Disorder. Psychology and Behavioral Sciences. 3(1), 33-40. 
